\title{
Molecular Mechanisms Involved in the Impairment of Boar Sperm Motility by Peroxynitrite-Induced Nitrosative Stress
}

\author{
Rebeca Serrano $^{\dagger}{ }$ Nicolás Garrido $^{\dagger}$, Jose A. Céspedes, Lauro González-Fernández ${ }^{\circledR}$, \\ Luis J. García-Marín and María J. Bragado *(i)
}

Research Group of Intracellular Signaling and Technology of Reproduction (Research Institute INBIO G+C), University of Extremadura, 10003 Cáceres, Spain; rebecasp@unex.es (R.S.); ngarridoff@unex.es (N.G.); jcespede@alumnos.unex.es (J.A.C.); lgonfer@unex.es (L.G.-F.); ljgarcia@unex.es (L.J.G.-M.)

* Correspondence: jbragado@unex.es

+ Both authors contributed equally as first author of this study.

Received: 20 January 2020; Accepted: 9 February 2020; Published: 11 February 2020

\begin{abstract}
Excessive levels of reactive nitrogen species (RNS) produce nitrosative stress. Among RNS is peroxynitrite, a highly reactive free radical generated when nitric oxide reacts with superoxide anion. Peroxynitrite effects have been mainly studied in somatic cells, and in spermatozoa the majority of studies are focused in humans. The aim of this study is to investigate the in vitro peroxynitrite effect on boar spermatozoa functions and the molecular mechanisms involved. Spermatozoa were exposed to the donor 3-morpholinosydnonimine (SIN-1) in non-capacitating or capacitating medium, motility was evaluated by CASA, functional parameters by flow cytometry and sperm protein phosphorylation by Western blotting. SIN-1 treatment, that significantly increases peroxynitrite levels in boar spermatozoa, potentiates the capacitating-stimulated phosphorylation of cAMP-dependent protein kinase 1 (PKA) substrates and GSK-3 $\alpha$. SIN-1 induced peroxynitrite does not decrease sperm viability, but significantly reduces sperm motility, progressive motility, velocities and motility coefficients. Concomitantly, peroxynitrite does not affect mitochondrial membrane potential, plasma membrane fluidity, or A23187-induced acrosome reaction. However, peroxynitrite significantly increases sperm lipid peroxidation in both media. In conclusion, peroxynitrite compromises boar sperm motility without affecting mitochondrial activity. Although peroxynitrite potentiates the phosphorylation of pathways leading to sperm motility, it also causes oxidative stress that might explain, at least partially, the motility impairment.
\end{abstract}

Keywords: boar spermatozoa; motility; peroxynitrite; viability; lipid peroxidation; phosphorylation; PKA; GSK-3 $\alpha$

\section{Introduction}

Oxidative stress occurs as a result of an imbalance of antioxidant defence mechanisms and free radicals production such as reactive oxygen species (ROS), which also include nitrogen-containing compounds, collectively named reactive nitrogen species (RNS). Low and/or regulated concentrations of cellular RNS (below $\mu \mathrm{M}$ range) play important roles in the physiological function in spermatozoa [1-3]. However, when RNS are produced at high concentrations can lead to so-called nitrosative stress that causes adverse effects in mammalian spermatozoa [4-10], specifically in their function and fertilizing ability [11]. The RNS include peroxynitrite anion $\left(\mathrm{ONOO}^{-}\right)$, nitrogen dioxide, nitroxyl ion, nitrosyl-containing compounds, and nitric oxide (NO). Under physiological conditions, mammalian spermatozoa produce the diffusible free radical $\mathrm{NO}[1,12]$ that in appropriate levels contributes to regulate sperm function $[2,3,12-14]$. Nitric oxide can react with superoxide anion $\left(\mathrm{O}_{2}{ }^{\bullet-}\right)$, also produced 
physiologically by spermatozoa, generating peroxynitrite $\left(\mathrm{ONOO}^{-}\right)$by a very fast and irreversible reaction [13] due to its exothermic nature [15]. In the same way, peroxynitrite can diffuse into the cells and even cross cell membranes and at low concentrations contribute to modulate sperm functions, mainly capacitation, as demonstrated in human spermatozoa [13] or in cryopreserved bovine spermatozoa, where $\mathrm{ONOO}^{-}$might also act as an inducer of sperm capacitation [16]. However, peroxynitrite molecule has been involved in some diseases (reviewed in [17]), because it is a strong oxidizing and/or nitrating agent that covalently binds to a variety of biomolecules causing lipid peroxidation, protein oxidation, nitration of the aromatic-side chains of amino acids as tyrosine and tryptophan, DNA oxidation, and inactivation of different enzymes. Therefore, $\mathrm{ONOO}^{-}$causes oxidative stress that promotes protein damage by direct oxidation of proteins side-chain, but also by adduction of secondary products resulting from the oxidation of polyunsaturated fatty acids, lipid peroxidation [18].

The molecular and functional effects of nitrosative stress induced by high concentrations of $\mathrm{ONOO}^{-}$ in spermatozoa have been mainly investigated in the human species $[5,7,8,10,13,19]$, where ROS and RNS promote a dose dependent increase of sperm tyrosine-nitrated proteins and S-glutathionylation and impair sperm motility and capacitation $[5,13]$. Among negative effects, a positive correlation between RNS and human sperm DNA fragmentation has been demonstrated [20]. Considering specifically $\mathrm{ONOO}^{-}$effects, it has been shown a negative correlation between $\mathrm{ONOO}^{-}$levels and human sperm morphology and motility parameters [9,20]. In fact, Vignini et al., (2006) [9] demonstrated that spermatozoa from normospermic patients have lower peroxynitrite levels, higher values of kinetic parameters and a decrease in tyrosine nitration compared to asthenozoospermic infertile patients. In addition, it had been demonstrated that in vitro exposure of human spermatozoa to $\mathrm{ONOO}^{-}$cause a decrease in total sulfhydryl groups and in motility, in parallel to an increase in lipid peroxidation [21]. Later, the in vitro exposure of human spermatozoa to peroxynitrite has been approached using a donor molecule, 3-morpholinosydnonimine (SIN-1), which effectively generates $\mathrm{ONOO}^{-}$in spermatozoa [7]. Using SIN-1, it has been demonstrated that peroxynitrite-induced nitrosative stress impairs vital functions of human spermatozoa including motility [7], via an alteration of the mitochondrial membrane potential, impairment of sperm ATP production [8], and an increased in thiol groups oxidation of sperm proteins [10], without affecting sperm viability [7]. At longer times, peroxynitrite-mediated nitrosative stress induces a type of cell death known as mitochondrial permeability transition (MPT)-driven necrosis in human spermatozoa [19].

As mentioned before, the majority of studies have evaluated the effect of nitrosative stress induced by $\mathrm{ONOO}^{-}$on spermatozoa from humans. However, no studies have investigated the in vitro effect of peroxynitrite in boar spermatozoa function, as previous works in this species have focused on oxidative stress induced by ROS, especially during semen preservation at $17^{\circ} \mathrm{C}$. Therefore, the aim of this work is to study the in vitro effects of peroxynitrite, generated by the donor molecule SIN-1, on the main functional processes of boar spermatozoa and the intracellular signalling pathways involved.

\section{Results}

\subsection{Effect of 3-Morpholinosydnonimine (SIN-1) Induced-Peroxynitrite in the Motility of Boar Spermatozoa}

The in vitro effect of peroxynitrite in boar sperm motility was evaluated using different concentrations of the donor molecule, SIN-1, in both media, non-capacitating (TBM) and capacitating (TCM). As observed in Figure 1, SIN-1 leads to a concentration dependent reduction in the percentage of motile spermatozoa in both media, although there is a clear difference between them as the reduction in sperm motility induced by SIN-1 is stronger in TBM than in TCM at the same SIN-1 concentrations. Thus, whereas the reduction in the number of motile spermatozoa is statistically significant at concentrations of $0.1,0.2$, and $0.4 \mathrm{mM}$ in TBM (Figure 1A), in TCM there is not a visible effect at $0.1 \mathrm{mM}$ and the modest reduction induced by $0.4 \mathrm{mM}$ is not statistically significant (Figure 1B). Therefore, in view of the weaker effect of SIN-1 in TCM we decided to study higher concentrations of SIN-1 in this medium (0.8 and 
$1 \mathrm{mM}$ ). As observed in Figure 1B, these SIN-1 concentrations significantly reduced the percentage of motile spermatozoa but, again, their effect in TCM is weaker than in TBM medium. Thus, the maximal reduction in TBM $(92 \%)$ occurs at $0.4 \mathrm{mM}$, where only $4 \%$ spermatozoa remain motile, whereas in TCM the maximal reduction in motility is about $40 \%$ at $0.8-1 \mathrm{mM}$, where $42 \%$ spermatozoa are motile. Considering these results and for the experiments of this work, we decided to use SIN-1 concentrations of $0.4 \mathrm{mM}$ when incubating in TBM and 0.4 and $1 \mathrm{mM}$ for TCM.
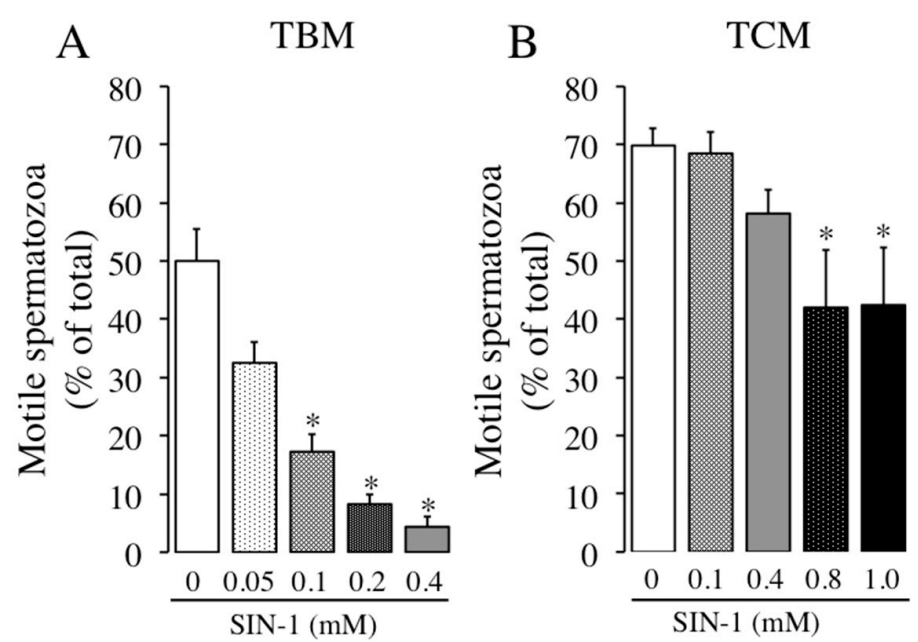

Figure 1. Effects of 3-morpholinosydnonimine (SIN-1) induced-peroxynitrite in the percentage of motile spermatozoa. Boar spermatozoa were incubated in non-capacitating media (TBM) (A) or capacitating media (TCM) (B) at $38.5^{\circ} \mathrm{C}$ in the absence (white histograms) or presence of different concentrations of SIN-1 (0.05-1 mM, filled histograms) for $1 \mathrm{~h}$. The percentage of motile spermatozoa was evaluated by ISAS $^{\circledR}$ system. This experiment was performed 8 times $(n=8)$ and results are expressed as the mean of the percentage of total spermatozoa \pm standard error of the mean (SEM). Statistical differences are shown with * $(p<0.05)$.

The effects of SIN-1 in other motility parameters as the percentages of progressive motile and rapid + progressive motile spermatozoa in both media are shown in Figure 2. Interestingly, SIN-1 treatment leads to a significant reduction in the percentage of progressive motile spermatozoa (Figure 2A) in both TBM $(0.4 \mathrm{mM})$ and in TCM $(1 \mathrm{mM})$. The inhibitory effect of SIN-1 is stronger in TBM $(93 \%$ reduction, where $0.4 \mathrm{mM}$ reduces the progressive motile spermatozoa to only $3 \%)$, than in TCM (39\% decrease, where there is $36 \%$ of progressive motile spermatozoa). Treatment with SIN-1 in TCM causes a significant reduction (94\%) in rapid + progressive motility parameter in a concentration-dependent manner, decreasing to only $3 \%$ of rapid + progressive spermatozoa when incubating with $1 \mathrm{mM}$ (Figure 2B). As expected, in TBM medium the rapid + progressive spermatozoa are almost undetectable $(0.8 \%)$ in absence of SIN-1, making difficult to evaluate the SIN-1 effect under these conditions. 


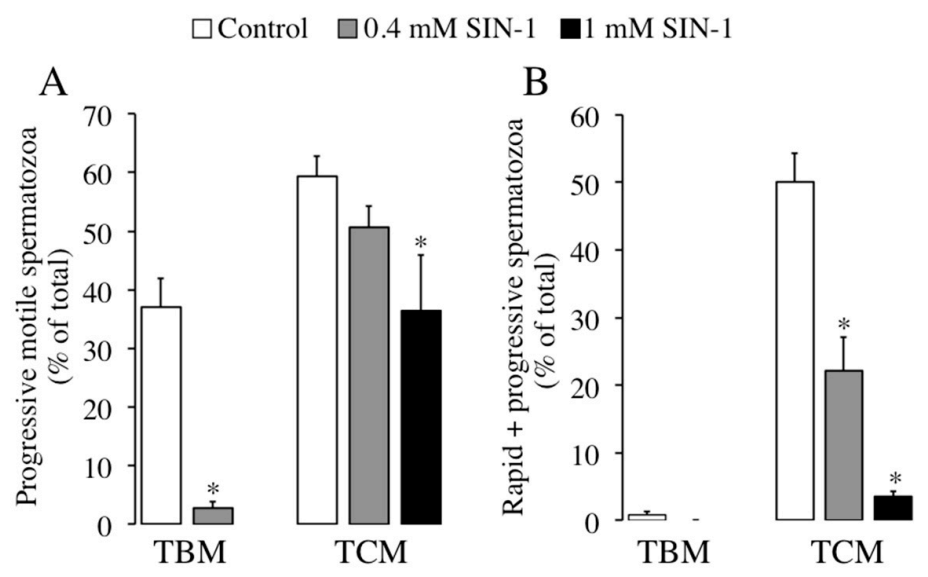

Figure 2. Effects of SIN-1 induced-peroxynitrite in the percentages of progressive motile and rapid + progressive motile boar spermatozoa. Spermatozoa were incubated in TBM or TCM at $38.5^{\circ} \mathrm{C}$ in the absence (white histograms) or the presence of indicated concentrations of SIN-1 (filled histograms) for $1 \mathrm{~h}$. Sperm motility parameters were evaluated by ISAS ${ }^{\circledR}$ system: the percentages of motile spermatozoa with progressive motility (A) and rapid and progressive motility (B) are shown. This experiment was performed 8 times $(n=8)$ and results are expressed as the mean of the percentage of total sperm \pm SEM. Statistical differences are shown with ${ }^{*}(p<0.05)$.

We further evaluated the effect of SIN-1-induced peroxynitrite in other motility parameters evaluated by CASA, such as spermatozoa velocities. As observed in Figure 3, SIN-1 incubation either in TBM or TCM causes a significant and concentration-dependent reduction in any sperm velocity studied: curvilinear VCL (Figure 3A), straight-linear VSL (Figure 3B) or the average VAP (Figure 3C).

\section{$\square$ Control $\square 0.4 \mathrm{mM} \mathrm{SIN-1} \square 1 \mathrm{mM} \mathrm{SIN-1}$}



TBM


Figure 3. Effects of SIN-1 induced-peroxynitrite in boar spermatozoa velocities. Boar spermatozoa were incubated in TBM or TCM at $38.5^{\circ} \mathrm{C}$ in the absence (white histograms) or presence of indicated concentrations of SIN-1 (filled histograms) for $1 \mathrm{~h}$. Boar sperm velocities were evaluated by ISAS ${ }^{\circledR}$ system: curvilinear velocity VCL (A), straight-linear velocity VSL (B), and average velocity VAP (C) expressed as $\mu \mathrm{m} / \mathrm{s}$ are shown. This experiment was performed 8 times $(n=8)$ and results are expressed as the mean of the percentage of total sperm \pm SEM. Statistical differences are shown with * $(p<0.05)$.

This significant effect is detected at $0.4 \mathrm{mM}$ in both media and the highest reductions in sperm velocity are achieved in TBM with $0.4 \mathrm{mM}$ of SIN-1 for VSL (70\% reduction) and in TCM with $1 \mathrm{mM}$ for VSL (60\% reduction). Moreover, SIN-1 significantly affects others spermatozoa motility coefficients analysed in Table 1. When spermatozoa are incubated with SIN-1 in TBM, the coefficients of straightness (STR) and the beat cross frequency (BCF) are significantly reduced, whereas in TCM, the amplitude of lateral sperm head displacement (ALH) is significantly reduced. 
Table 1. Effects of SIN-1 induced-peroxynitrite in boar spermatozoa motility coefficients.

\begin{tabular}{cccccc}
\hline Treatment & LIN (\%) & STR (\%) & WOB (\%) & ALH $(\boldsymbol{\mu m})$ & BCF (Hz) \\
\hline TBM & $58.30 \pm 3.31$ & $82.88 \pm 1.98$ & $67.15 \pm 2.91$ & $1.86 \pm 0.14$ & $6.82 \pm 0.61$ \\
$+0.4 \mathrm{mM} \mathrm{SIN-1}$ & $52.17 \pm 5.90$ & $70.49 \pm 4.41^{*}$ & $69.26 \pm 4.04$ & $1.18 \pm 0.26$ & $2.02 \pm 0.40^{*}$ \\
TCM & $78.86 \pm 2.00$ & $90.88 \pm 1.25$ & $83.49 \pm 1.25$ & $2.24 \pm 0.10$ & $7.54 \pm 0.78$ \\
+0.4 mM SIN-1 & $80.66 \pm 1.64$ & $91.94 \pm 0.90$ & $84.81 \pm 1.07$ & $1.71 \pm 0.07 *$ & $8.35 \pm 0.25$ \\
+1.0 mM SIN-1 & $75.48 \pm 3.06$ & $88.02 \pm 1.68$ & $83.14 \pm 2.00$ & $1.36 \pm 0.08^{*}$ & $5.50 \pm 0.66$ \\
\hline
\end{tabular}

Boar spermatozoa were incubated in TBM or TCM at $38.5^{\circ} \mathrm{C}$ in the absence or presence of indicated concentrations of SIN-1 (mM) for $1 \mathrm{~h}$. Sperm kinematic parameters were evaluated by ISAS ${ }^{\circledR}$ system: linearity (LIN, in \%); straightness (STR, in \%); wobble movement coefficient (WOB, in \%); beat cross frequency (BCF, in $\mathrm{Hz}$ ) and amplitude of lateral sperm head displacement (ALH, in $\mu \mathrm{m})$. This experiment was performed 8 times $(n=8)$ and values are expressed as the mean \pm SEM. Statistical differences from their own control are shown with * $(p<0.05)$.

\subsection{The Treatment with SIN-1 Effectively Generates RNS, as Peroxynitrite, in Boar Spermatozoa}

We next aimed to confirm that the exposure of boar spermatozoa to SIN-1 effectively generates intracellular peroxynitrite, as it is published in human spermatozoa [7]. The generation of peroxynitrite following exposure to SIN-1 was evaluated by flow cytometry using dihydrorhodamine 123 (DHR 123), which becomes highly fluorescent after oxidation to rhodamine 123 by peroxynitrite or any RNS. The treatment of spermatozoa with different SIN-1 concentrations $(0.05$ to $0.4 \mathrm{mM})$ during $1 \mathrm{~h}$ at $38.5^{\circ} \mathrm{C}$ in TBM resulted in a concentration-dependent increase in the relative intensity of fluorescence (RFI) due to oxidized-rhodamine by RNS (Figure $4 \mathrm{~A}$ ), which is statistically significant at SIN-1 concentrations of $0.1,0.2$, and $0.4 \mathrm{mM}$. In order to compare the effect of SIN-1 as peroxynitrite-inducer in different sperm incubation media, spermatozoa were exposed to SIN-1 in TCM. As observed in Figure 4, SIN-1 $(0.4 \mathrm{mM})$ induces a significant increase in sperm peroxynitrite or RNS amount in both media TBM (Figure 4A) and TCM (Figure 4B). The ability of the same concentration of SIN-1 (0.4 mM) to increase peroxynitrite levels in spermatozoa is similar in both media (24-fold increase). A greater concentration of SIN-1 (1 mM) significantly increases by 40 times the amount of peroxynitrite in boar spermatozoa.
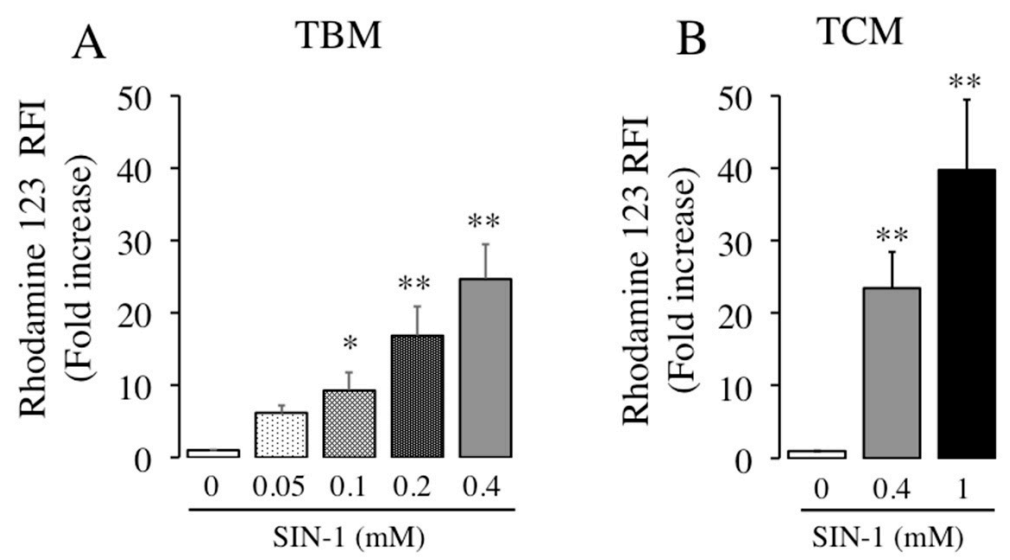

Figure 4. Concentration-dependent generation of peroxynitrite by SIN-1 in boar spermatozoa. Boar spermatozoa were incubated in TBM (A) or TCM (B) in the absence (white histograms) and presence of indicated concentrations of SIN-1 (filled histograms). The levels of reactive nitrogen species (RNS) induced by SIN-1 were evaluated by flow cytometry using DHR 123 as a probe. These experiments were performed 6 times $(n=6)$ and results are expressed as the fold increase of Relative Fluorescence Intensity (RFI) of DHR $123 \pm$ SEM. Statistical differences are shown with * $(p<0.05)$ and ${ }^{* *}(p<0.01)$.

\subsection{Effect of SIN-1 Induced-Peroxynitrite in the Viability of Boar Spermatozoa}

Sperm viability after $1 \mathrm{~h}$ of incubation in control spermatozoa (absence of SIN-1, white histograms) is lower in TCM (60\% of total) than in TBM ( $88 \%$ of total) (Figure 5), as previously described [22]. The exposure of spermatozoa to SIN-1 in TBM does not affect the percentage of viable spermatozoa. 
However, there is a small, although reproducible, effect of SIN-1 increasing sperm viability or preventing the loss of cell viability observed in TCM, where $68 \%$ and $73 \%$ of spermatozoa remain viable after $0.4 \mathrm{mM}$ and $1 \mathrm{mM}$ of SIN-1, respectively, compared to $60 \%$ in the absence of SIN-1 (Figure 5). This modest preventive effect of SIN-1 in the loss of spermatozoa viability occurring in TCM is concentration-dependent and is statistically significant at $1 \mathrm{mM}$ of SIN-1.

\section{A}



B
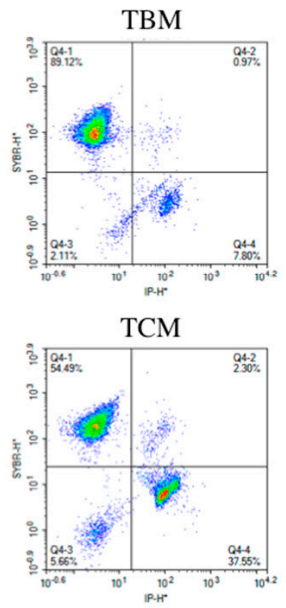
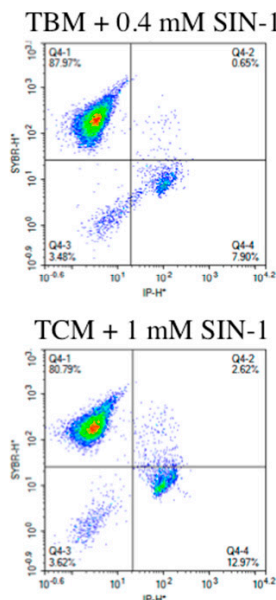

Figure 5. Effect of SIN-1 induced-peroxynitrite in boar spermatozoa viability. (A) Boar spermatozoa were incubated in TBM or TCM at $38.5^{\circ} \mathrm{C}$ in the absence (white histograms) or presence of SIN-1 (filled histograms) for $1 \mathrm{~h}$. (B) Representative two-dimensional SYBR-14 fluorescence versus PI fluorescence dot plots for sperm samples incubated in presence or absence of SIN-1 are shown. This experiment was performed 8 times $(n=8)$ and the results are expressed as the percentage of SYBR14-positive and PI-negative spermatozoa \pm SEM. Statistical differences are shown with * $(p<0.05)$.

\subsection{Effect of SIN-1 Induced-Peroxynitrite in the Mitochondrial Membrane Potential $(\Delta \Psi m)$ of Boar Spermatozoa}

The action of peroxynitrite induced by SIN-1 in the sperm mitochondrial membrane potential, $\Delta \Psi \mathrm{m}$, was evaluated after incubation of boar spermatozoa in both media TBM and TCM in the presence or absence of different SIN-1 concentrations. As observed in Figure 6A, an increase in peroxynitrite caused by SIN-1 does not significantly modify the population of boar spermatozoa presenting relative higher $\Delta \Psi \mathrm{m}$ at any concentration or incubation medium studied.

\subsection{Effect of SIN-1 Induced-Peroxynitrite in the Acrosome Reaction Induced by A23187 in Boar Spermatozoa}

We analyzed the effect of peroxynitrite generated by SIN-1 on the acrosome reaction of boar spermatozoa induced by calcium ionophore A23187 in TBM and TCM, using PNA-FITC and PI as probes for flow cytometry. As observed in Figure 6B, the percentage of live acrosome-reacted spermatozoa induced by A23187 in a non-capacitating medium is small (12\%) and is not significantly affected by SIN-1 treatment. When boar spermatozoa are incubated in TCM, A23187 effectively triggers acrosome reaction (3-fold increase; white histograms) and SIN-1 induced-RNS does not significantly affect the percentage of $\mathrm{PNA}^{+} / \mathrm{PI}^{-}$spermatozoa, although a slight decrease is detected (grey and black histograms). 


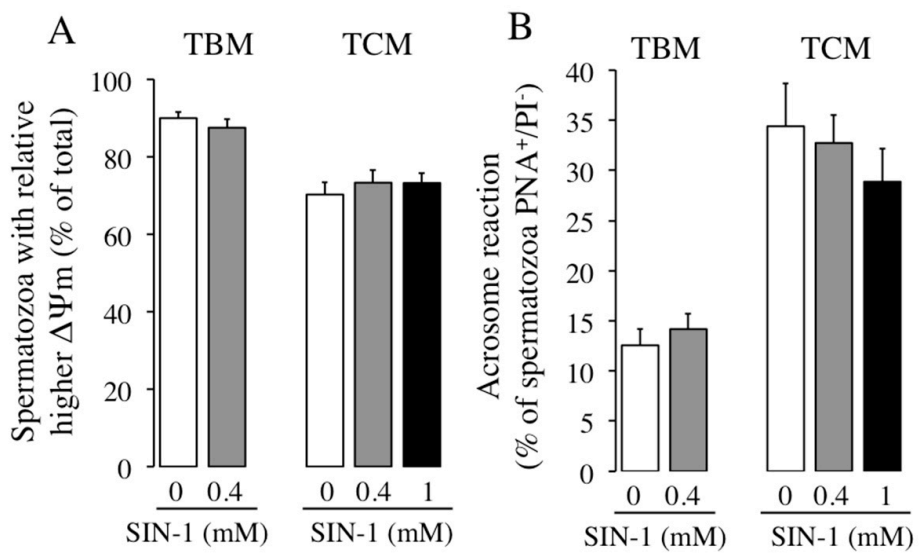

Figure 6. Effect of SIN-1 induced-peroxynitrite in mitochondrial membrane potential and in the acrosome reaction induced by calcium ionophore A23187 on boar spermatozoa. Boar spermatozoa were incubated in TBM or TCM at $38.5^{\circ} \mathrm{C}$ in the absence (white histograms) or presence of SIN-1 (filled histograms) for $1 \mathrm{~h}$. (A) Results are expressed as the percentage of spermatozoa exhibiting relative higher $\Delta \Psi \mathrm{m}$ from the total sperm cells analyzed. (B) Percentage of live acrosome-reacted spermatozoa $\left(\mathrm{PNA}^{+} / \mathrm{PI}^{-}\right)$induced by A23187. These experiments were performed 8 times in $\mathrm{A}(n=8)$ and 7 times in $\mathrm{B}(n=7)$ and data are expressed as the mean \pm SEM. No statistical differences were found $(p<0.05)$.

\subsection{Effect of SIN-1 Induced-Peroxynitrite in Lipid Peroxidation Degree and Lipid Organization in the Plasma Membrane of Boar Spermatozoa}

We next investigated whether SIN-1 affects the degree of plasma membrane lipid organization, evaluated by flow cytometry, in boar spermatozoa. Results in Figure 7A show that lipid disorganization of plasma membrane is unaffected by SIN-1-induced peroxynitrite, as the RFI of spermatozoa M540high in living spermatozoa are similar in control and treated spermatozoa. This lack of SIN-1 effect is observed in any sperm incubation medium (Figure 7A).
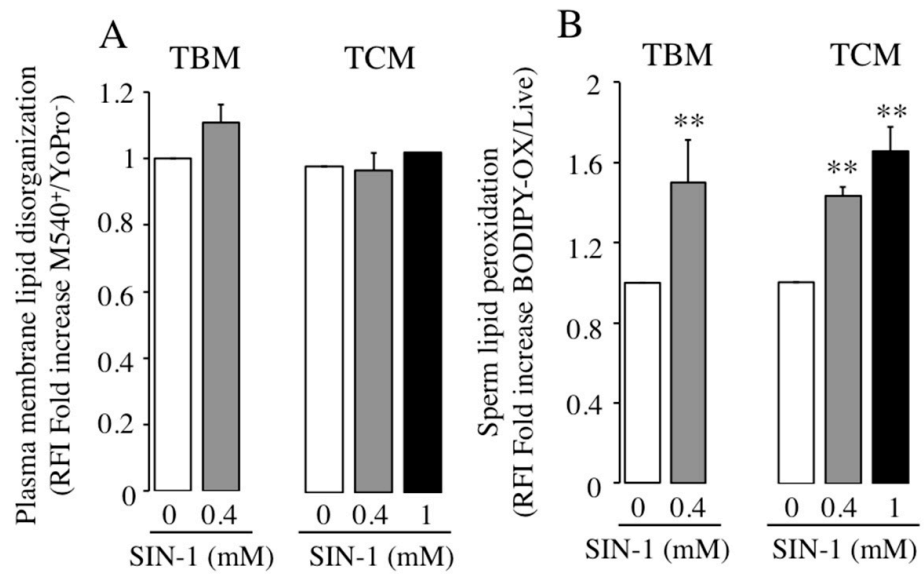

Figure 7. Effect of SIN-1 induced-peroxynitrite in lipid peroxidation and in plasma membrane lipid organization on boar spermatozoa. Boar spermatozoa were incubated in TBM or TCM in the absence (white bars) or presence of indicated concentrations of SIN-1 (filled bars) for $1 \mathrm{~h}$ at $38.5^{\circ} \mathrm{C}$. (A) Plasma membrane lipid disorganization levels in viable boar spermatozoa (M540 high $/$ YoPro- $1^{-}$). (B) Lipid peroxidation levels in viable boar spermatozoa (C11-BODIPY581/591/L10120 ${ }^{-}$). These experiments were performed 6 times $(n=6)$. Results are expressed as the mean \pm SEM of fold increase in Relative Fluorescence Intensity (RFI). Statistical differences are shown with ${ }^{* *}(p<0.01)$. 
In order to investigate the effect of SIN-1 induced peroxynitrite in the sperm lipid peroxidation, we used the fluorescent lipid probe C11-BODIPY ${ }^{581 / 591}$ by flow cytometry. Interestingly, SIN-1-induced peroxynitrite significantly raises lipid peroxidation levels in boar spermatozoa in any incubation medium, TBM or TCM (Figure 7B). In a capacitating medium, SIN-1 treatment increases sperm lipid peroxidation in a concentration-dependent manner.

2.7. Effects of SIN-1 Induced-Peroxynitrite in the Signaling Pathways Mediated by cAMP-Dependent Protein Kinase 1 (PKA) and Glycogen Synthase Kinase 3 (GSK-3) in Boar Spermatozoa

We next investigated whether SIN-1-induced peroxynitrite affects those key intracellular signaling pathways mediated by protein phosphorylation that regulate boar sperm motility. As observed in Figure 8, the treatment of boar spermatozoa with SIN-1 modifies the phosphorylation state of the majority of substrates of PKA (indicated by arrows). The increase in the phosphorylation occurs in both media, TBM and TCM, although is more intense in TCM, where a concentration-dependent phosphorylation is detected.

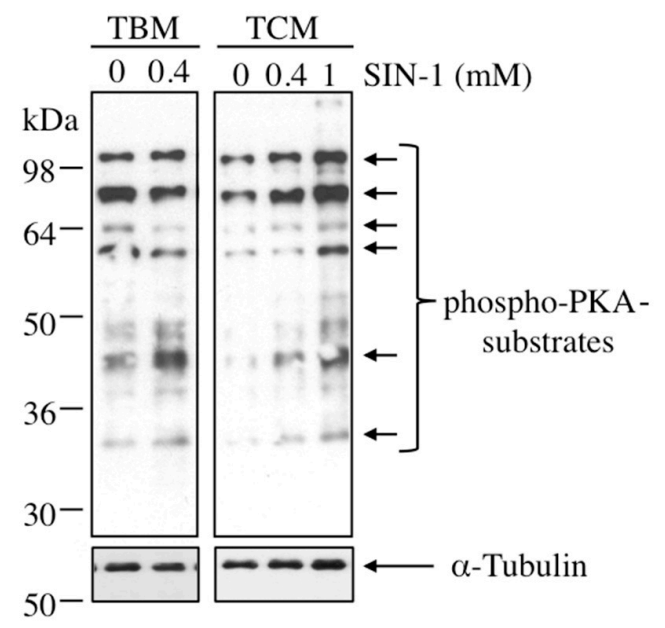

Figure 8. Effect of SIN-1 induced-peroxynitrite in the phosphorylation of PKA-substrates on boar spermatozoa. Spermatozoa were incubated in TBM or TCM medium at the indicated concentrations of SIN-1 at $38.5{ }^{\circ} \mathrm{C}$ for $1 \mathrm{~h}$ and sperm proteins $(15 \mu \mathrm{g})$ analyzed by western blotting using anti-phospho-PKA-substrate as primary antibody (upper films). These experiments were performed 4 times and a representative film is shown. Loading controls using anti- $\alpha$-tubulin antibody (lower films) were performed in a parallel membrane. Arrows indicate the cross-reactive bands of sperm phosphorylated proteins that are substrates of PKA.

Regarding GSK-3, SIN-1-induced peroxynitrite leads to a clear increase in the phosphorylation state of the $\alpha$ isoform of this kinase (Figure 9). As occurs with the PKA substrates (Figure 8), the increase in phosphorylation of GSK-3 $\alpha$ is more pronounced in TCM medium (Figure 9B), where is also observed a concentration-dependent rise: 1.7 times at $0.4 \mathrm{mM}$ and 2.4 times at $1 \mathrm{mM}$. This GSK-3 $\alpha$ phosphorylation effect is statistically significant at both SIN-1 concentrations compared to untreated control. 
A

TBM

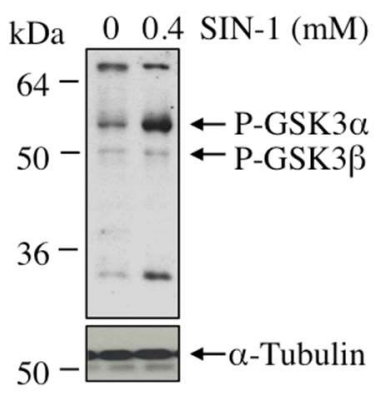

$\mathrm{B}$

TCM

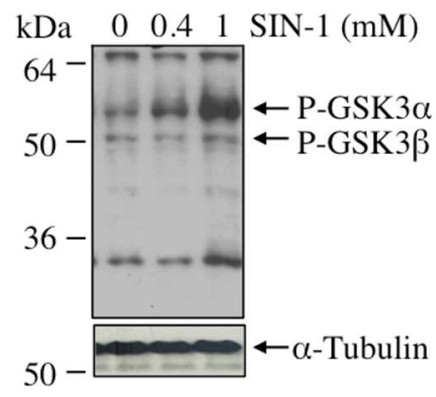

$\square$ Control $\quad \square 0.4 \mathrm{mM} \mathrm{SIN-1} \quad \mathbf{m}$ mM SIN-1

C

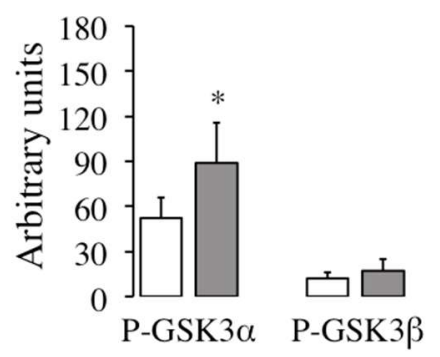

$\mathrm{D}$

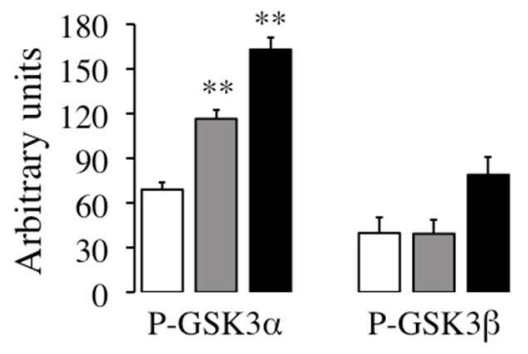

Figure 9. Effect of SIN-1 induced-peroxynitrite in the phosphorylation of GSK-3 on boar spermatozoa. Spermatozoa were incubated in TBM (A) or TCM medium (B) at the indicated concentrations of SIN-1 at $38.5^{\circ} \mathrm{C}$ for $1 \mathrm{~h}$ and sperm proteins $(15 \mu \mathrm{g})$ analyzed by Western blotting using anti-phospho GSK-3 $\alpha / \beta$ as primary antibody (upper films). These experiments were performed 4 times and representative films are shown. Loading controls using anti- $\alpha$-tubulin antibody (lower films) were performed for each experiment in the same membrane. $(\mathbf{C}, \mathbf{D})$ correspond to the quantification of bands in $(\mathbf{A}, \mathbf{B})$, respectively. Arrows indicate the cross-reactive sperm bands corresponding to phosphorylated GSK-3 $\alpha$ (P-GSK-3 $\alpha$ ) and GSK-3 $\beta$ (P-GSK-3 $\beta$ ) and also $\alpha$-tubulin. Densitometry analysis of each band is shown at the bottom image, values are expressed as arbitrary units; mean \pm SEM. Statistical differences are shown with ${ }^{* *}(p<0.01)$ and $*(p<0.05)$.

\section{Discussion}

This study demonstrates that the generation of reactive nitrogen species (RNS), peroxynitrite, following exposure to the donor SIN-1 effectively occurs in boar spermatozoa, as it happens in human spermatozoa [7]. The increase in the intracellular $\mathrm{ONOO}^{-}$amount in boar spermatozoa is dependent of the SIN-1 concentration used ( 0.05 to $1 \mathrm{mM}$ ), which also agrees with the previous work in human spermatozoa [7]. Peroxynitrite generation and its effect in boar spermatozoa are also dependent on the incubation medium, which is supported by the study of Crow [23] showing that $\mathrm{ONOO}^{-}$cellular effects are dependent on the environment in which the anion is present. Interestingly, boar spermatozoa are more sensitive to SIN-1-induced $\mathrm{ONOO}^{-}$than human spermatozoa, as the inhibitory effect of sperm motility with the same SIN-1 concentration is greater in boar, even with only $1 \mathrm{~h}$ of incubation versus $4 \mathrm{~h}$ in human [7]. This suggests that sensitivity of spermatozoa to RNS, as peroxynitrite, varies with the species studied.

This study shows that SIN-1-induced $\mathrm{ONOO}^{-}$causes a clear reduction on total, rapid and progressive motility in boar spermatozoa, as well as on main sperm kinetic parameters. This inhibition of sperm motility is dependent of the $\mathrm{ONOO}^{-}$concentration and occurs in both sperm incubation media, although is clearly more intense in TBM (92\% reduction with $0.4 \mathrm{mM}$ SIN-1) than in TCM (17\% reduction with $0.4 \mathrm{mM}$ SIN-1). These data support the previous idea that peroxynitrite effects are dependent on the environment [23], and indicate that $\mathrm{ONOO}^{-}$effects in boar spermatozoa are effectively 
influenced by the composition of extracellular medium, as the exposition to calcium, bicarbonate or BSA (TCM) clearly prevents the adverse $\mathrm{ONOO}^{-}$effect in sperm motility observed in the absence of these stimuli (TBM). In fact, BSA has been pointed as a protective factor of boar sperm quality during liquid storage at $17^{\circ} \mathrm{C}$, acting as an antioxidant [24]. Moreover, at physiological temperature, BSA is also able to modulate boar sperm motility effect induced by the AMPK activator A769662 [22]. In this work, BSA is not playing an antioxidant role, as the level of sperm lipid peroxidation is the same in presence or absence of BSA, but it could be reasonable to point to BSA as a stimulus that might be modulating the adverse ONNO- effect in sperm motility. Future experiments are needed to clarify this particular issue.

The fact that SIN-1-induced $\mathrm{ONOO}^{-}$inhibits boar spermatozoa progressive motility and main kinetic parameters is in total agreement with studies performed with SIN-1 in human spermatozoa by Uribe et al., [7], which conclude that $\mathrm{ONOO}^{-}$impairs spermatozoa essential functions, as motility. Previously, Öztezcan et al., [21] demonstrated that exogenous peroxynitrite added to human spermatozoa decreased motility and sperm velocities. Later, Vignini et al., [9] showed that endogenous $\mathrm{ONOO}^{-}$produced physiologically in human spermatozoa negatively affected motility, as spermatozoa from asthenozoospermic infertile patients have higher $\mathrm{ONOO}^{-}$levels and lower values of kinetic parameters compared to normospermic fertile patients. However, one study reported that the percentage of human motile spermatozoa was unaffected by peroxynitrite or SIN-1 and that the sperm velocity VCL increased [13]. Different effects of SIN-1 on sperm motility between studies can be attributed to the distinct species studied and also to the incubation times used: $1 \mathrm{~h}$ in boar, $4 \mathrm{~h}$ in human [7], or $8 \mathrm{~h}$ in human [13], as $\mathrm{ONOO}^{-}$amount in spermatozoa generated by SIN-1 greatly depends on the incubation time [7].

A reduction in sperm motility could be explained by sperm death. Interestingly, in the absence of SIN-1, boar sperm viability is lower in TCM than in TBM, which agree with previous results showing that sperm viability decreases in TCM in a time-dependent manner [22]. In the presence of SIN-1, the reduction in sperm motility cannot be attributed to a death of sperm cells, as boar sperm viability is not decreased by SIN-1, which agrees with previous reports in cryopreserved bovine spermatozoa [16] and also in human spermatozoa treated with SIN-1 for longer incubation time, $4 \mathrm{~h} \mathrm{[7].} \mathrm{In} \mathrm{addition,} \mathrm{our}$ data focused at the sperm plasma membrane level, reveal that $\mathrm{ONOO}^{-}$does not cause any visible effect in its fluidity, indicating that, at least in our conditions, the impairment in boar sperm motility induced by SIN-1 cannot be attributed to lipid disorganization at the plasma membrane. There are not previous studies investigating SIN-1 effect in this sperm parameter.

One possible explanation for the impairment of boar sperm motility is based on the fact that $\mathrm{ONOO}^{-}$could alter the mitochondrial activity [7]. However, this is not the case in boar spermatozoa, as the mitochondrial membrane potential $(\Delta \Psi \mathrm{m})$ is unaffected by SIN-1 in our conditions. By contrast, in human spermatozoa SIN-1 concentration-dependently decreased the $\Delta \Psi \mathrm{m}$ after $1 \mathrm{~h} \mathrm{[7]}$, and inhibits sperm ATP production after $4 \mathrm{~h}$ by affecting metabolic pathways of mitochondrial OXPHOS and glycolysis [8]. Different results about sperm $\Delta \Psi \mathrm{m}$ could be attributed to the different species studied (boar or human) because, as mentioned before, there is a species-specific sensitivity to SIN-1 and also to the incubation time with the $\mathrm{ONOO}^{-}$donor, $1 \mathrm{~h}$ versus $4 \mathrm{~h}$ [8]. At longer incubation times, $24 \mathrm{~h}$, SIN-1 induced-nitrosative stress causes human sperm death due to an induction of mitochondrial permeability transition-driven necrosis [19].

This study suggests that SIN-1-induced $\mathrm{ONOO}^{-}$does not affect boar sperm capacitation, evaluated as the sperm response to acrosome reaction induced by calcium ionophore. Both sperm processes are modulated by $\mathrm{NO}[25]$ and it has been proposed that $\mathrm{ONOO}^{-}$also might modulate sperm capacitation [26], as reported in human spermatozoa [13] and in cryopreserved bovine spermatozoa [16], where SIN-1 increased the sperm acrosome reaction induced by different stimuli. Specifically, in boar spermatozoa there are discrepancies regarding the involvement of NO pathway in the acrosome reaction. Thus, Staicu et al., (2019) [27] recently found that exogenous NO does not affect acrosome reaction, whereas Hou et al., (2008) [28] described that NO donor increases the number of acrosome-reacted 
spermatozoa. Our results with ONOO- support the idea that the pathway of NO, including related RNS, is not likely involved in the acrosome reaction of boar spermatozoa.

Peroxynitrite, as a strong oxidant, causes oxidative stress that promotes protein damage by direct oxidation and by adduction of secondary products resulting from the oxidation of polyunsaturated fatty acids $[18,29]$. In fact, in this study, sperm peroxynitrite generated after $1 \mathrm{~h}$ of incubation with SIN-1 causes a marked increase in lipid peroxidation in boar spermatozoa. A previous study points to an increase in lipid peroxidation due to $\mathrm{ONOO}^{-}$as the cause of human sperm dysfunction [21]. Thus, we propose that the motility impairment in boar spermatozoa induced by SIN-1 can be attributed, at least in part, to an oxidative stress induced by peroxynitrite. This conclusion is supported by previous studies in human spermatozoa reporting that oxidative stress impairs human spermatozoa function $[5,30,31]$ and that lipid peroxidation effectively causes loss of human sperm motility [32]. A consequence derived from oxidative stress is that $\mathrm{ONOO}^{-}$rapidly reacts with the sulfhydryl group, as reported in human spermatozoa, where the adverse effect of peroxynitrite in motility is mediated by an increased oxidation in the thiol groups of sperm proteins [10] or by depletion of total sulphydryl group in sperm proteins [21]. In addition, $\mathrm{ONOO}^{-}$can cause tyrosine nitration, mostly in specific functional domains of sperm proteins, promoting structure and conformations changes that may be responsible for the alteration or inactivation of sperm proteins function $[13,33]$. Although we have not specifically evaluated protein tyrosine nitration or thiol oxidation groups in boar spermatozoa, we demonstrate that lipid peroxidation occurs in response to $\mathrm{ONOO}^{-}$and thus, we propose that those sperm proteins very sensitive to oxidative stress that are involved in molecular mechanisms of sperm motility can likely become oxidized and inactivated by $\mathrm{ONOO}^{-}$, leading to an impairment in boar sperm motility.

Among other actions, peroxynitrite might function as cellular messenger $[13,26]$ and therefore this RNS might regulate sperm function through the modulation of intracellular signaling pathways, as it has been reported in human spermatozoa [34]. To our knowledge, this is the first study that demonstrates that SIN-1-induced $\mathrm{ONOO}^{-}$acts as a modulator of serine/threonine phosphorylation in boar spermatozoa. In fact, peroxynitrite promotes an increase in the phosphorylation of GSK-3 $\alpha$ and in sperm proteins that are substrates of PKA. Both signaling pathways, GSK-3 $\alpha$ and PKA, are essential in the regulation of boar sperm motility [35-37]. Part of our results with $\mathrm{ONOO}^{-}$are in line with a recent study in boar spermatozoa that found that phosphorylation of PKA substrates is significantly lower when using NO synthase inhibitors [27]. The peroxynitrite-induced increase in GSK-3 $\alpha$ phosphorylation is greater in TCM (2.4 fold-increase over control), than in TBM (1.7 fold-increase) as stimulating medium TCM alone is already promoting higher levels of phosphorylated GSK-3 $\alpha$ than the un-stimulating TBM. Thus, according to its regulatory role in motility $[35,36]$, the greater GSK-3 $\alpha$ phosphorylation induced by $\mathrm{ONOO}^{-}$would explain the greater percentage of sperm motility evaluated in TCM, where $40 \%$ of total spermatozoa still remain motile (0.8-1 mM SIN-1; Figure 1B). By contrast, the lower fold increase in GSK-3 $\alpha$ phosphorylation caused by peroxynitrite in TBM would account for much lower sperm motility under TBM, where only $4 \%$ of total spermatozoa are motile (0.4 mM SIN-1; Figure 1B). At the molecular level, the peroxynitrite-induced phosphorylation of PKA and GSK-3 $\alpha$ in boar spermatozoa can be explained by the fact that $\mathrm{ONOO}^{-}$, besides to stimulate guanylate cyclase and therefore increasing cGMP levels, can also increase cAMP levels when they are already stimulated by low concentrations of adenylate cyclase (AC) activators, as it has been demonstrated in platelets in response to $\mathrm{ONOO}^{-}$[38], and to NO donors [39]. Moreover, similar synergistic peroxynitrite effect has been described also in vascular smooth muscle cells when AC becomes activated with forskoline or sodium fluoride [40]. However, the elevating effect of $\mathrm{ONOO}^{-}$in the cAMP levels is not likely due to a direct action on the AC, but rather to an inhibition of phosphodiesterases, as found for phosphodiesterase type III in human platelets [38]. Based on these evidences in somatic cells, we can postulate that in boar spermatozoa also a synergistic effect between $\mathrm{ONOO}^{-}$and soluble AC (sAC) activators might be leading to an increase in sperm cAMP levels that could explain the increase observed in the phosphorylation of its downstream pathways, i.e., PKA substrates and GSK- $3 \alpha$, mainly in TCM medium that includes 
sAC activators. This molecular mechanism could also contribute to explain the small but significant increase in boar sperm viability due to $\mathrm{ONOO}^{-}$in TCM, where sperm sAC is activated, as it has been demonstrated that somatic cells, such as monocytes and macrophages, survive to $\mathrm{ONOO}^{-}$via a concomitant activation of PKA pathway [41]. Surprisingly, $\mathrm{ONOO}^{-}$raises an issue in boar spermatozoa: it leads to phosphorylation of two key signaling pathways involved in sperm motility but ultimately it inhibits sperm motility. We think that future investigation is needed to elucidate the exact molecular mechanisms triggered by $\mathrm{ONOO}^{-}$that lead to a reduction of sperm motility, but the most plausible explanation based in our results is that sperm oxidative stress is the ultimate cause of inactivation of proteins involved in sperm motility, independently of their phosphorylation state.

In conclusion, peroxynitrite compromises a vital function of the male gamete, the sperm motility, without affecting the mitochondrial membrane potential. Although peroxynitrite potentiates the phosphorylation of two serine/threonine kinases, PKA and GSK-3 $\alpha$, leading to sperm motility, it also causes oxidative stress that might contribute, at least partially, to explain the sperm motility impairment.

\section{Materials and Methods}

\subsection{Reagents and Sources}

3-Morpholinosydnonimine (SIN-1) and dihydrorhodamine 123 (DHR 123) probe were from ENZO Life Science Inc. (Farmingdate, NY, USA); Propidium iodide (PI), SYBR-14, and M540 and YoPro-1 probes were purchased from Molecular Probes (Leiden, The Netherlands); PNA-FITC and calcium ionophore A23187 were from Sigma-Aldrich (St Louis, MO, USA); C11-BODIPY 581/591 (4,4-difluoro-5(4-phenyl-1,3-butadienyl)-4- bora-3a, 4a-diaza-s-indacene-3-undecanoic acid)and JC-1 probes from Life Technologies Ltd (Grand Island, NY, USA); coulter isotone II diluent from Beckman Coulter Inc. (Brea, CA, USA); DC TM Protein Assays and $2 \times$ Laemmli Sample Buffer from Bio-Rad (Hercules, CA, USA). ECL detection kit and LIVE/DEAD ${ }^{\mathrm{TM}}$ Fixable Far Red Dead Cell Stain Kit (L10120) were from Thermo Scientific (Rockford, USA). Furthermore, the anti-phospho (Ser/Thr) PKA Substrate (\#9624) and anti-phospho (Ser21/9) GSK3 $\alpha / \beta$ (\#9331) polyclonal antibodies were from Cell Signaling Technology, Inc. (Beverly, MA, USA); the anti- $\alpha$-tubuline antibody (TU-02, \#SC-8035) was from Santa Cruz Biotechnology (Santa Cruz, CA, USA). All reagents used to prepare incubation media were purchased from Sigma-Aldrich (St. Louis, MO, USA).

\subsection{Spermatozoa Incubation Media}

Tyrode's basal medium (TBM; $96 \mathrm{mM} \mathrm{NaCl}, 4.7 \mathrm{mM} \mathrm{KCl}, 0.4 \mathrm{mM} \mathrm{MgSO}_{4}, 0.3 \mathrm{mM} \mathrm{NaH}{ }_{2} \mathrm{PO}_{4}$ ， $5.5 \mathrm{mM}$ glucose, $1 \mathrm{mM}$ sodium pyruvate, $21.6 \mathrm{mM}$ sodium lactate, $20 \mathrm{mM}$ HEPES, $5 \mathrm{mM}$ EGTA, and $0.02 \%$ PVA) was prepared and used as the non-capacitating medium. A variant of TBM was made omitting EGTA and adding $1 \mathrm{mM} \mathrm{CaCl}, 15 \mathrm{mM} \mathrm{NaHCO}_{3}$ and $3 \mathrm{mg} / \mathrm{mL}$ BSA, then it was equilibrated with $5 \% \mathrm{CO}_{2}$ in $\mathrm{O}_{2}$ and termed Tyrode's complete medium (TCM), a spermatozoa-capacitating medium. All media were prepared on the day of use and adjusted to $\mathrm{pH} 7.45$ with an osmolarity of 290-310 $\mathrm{mOsm} \mathrm{kg}^{-1}$.

\subsection{Boar Semen Collection and Experimental Treatment of Spermatozoa with 3-Morpholinosydnonimine (SIN-1)}

Sperm samples from Duroc boars (2-4 years old) were commercially obtained from a regional porcine company (Tecnogenext, S.L, Mérida, Spain), without any requirement of approval from the animal research review board of the University of Extremadura. All boars were housed in individual pens in an environmentally controlled building $\left(15-25^{\circ} \mathrm{C}\right)$ according to Regional Government and European regulations, and received the same diet. Fresh ejaculates were collected with the gloved hand technique and stored at $17^{\circ} \mathrm{C}$ before use in the laboratory. In order to minimize individual boar variations, samples from up to 3 animals were pooled using semen from no less than 12 boars in different combinations. Only semen pools with at least $80 \%$ morphologically normal spermatozoa were 
used. Semen was centrifuged at $900 \mathrm{~g}$ for $4 \mathrm{~min}$, washed with phosphate-buffered saline (PBS) and spermatozoa were placed in TBM or TCM medium to a final concentration of $40 \times 10^{6}$ spermatozoa $/ \mathrm{mL}$.

Depending on each experimental procedure, different volumes of spermatozoa samples ( 0.5 or $1.5 \mathrm{~mL}$ ) containing $40 \times 10^{6}$ spermatozoa $/ \mathrm{mL}$ were incubated in the presence or absence of 3-morpholinosydnonimine (SIN-1) at $38.5^{\circ} \mathrm{C}$ for $1 \mathrm{~h}$. When spermatozoa were incubated in TBM, incubation was performed in absence of $\mathrm{CO}_{2}$, whereas TCM treatment was performed in a humidified atmosphere of $5 \% \mathrm{CO}_{2}$. To confirm that SIN-1 is effectively a peroxynitrite donor in boar spermatozoa, samples were initially treated with or without different concentrations of SIN-1: $0.05,0.1,0.2,0.4$, and $1 \mathrm{mM}$. As a control sample, spermatozoa were incubated with the vehicle dimethyl sulfoxide (DMSO) at the highest concentration used $(0.4 \%$ in experiments including TBM and $1 \%$ in experiments under TCM).

\subsection{Flow Cytometry Analysis}

Flow cytometry analysis was performed using an ACEA NovoCyte ${ }^{\circledR}$ flow cytometer (ACEA Biosciences, Inc., San Diego, CA, USA) equipped with a three detection channels for blue laser (488 nm): BL-1 (530 $\pm 30 \mathrm{~nm}$ band pass filter); BL-2 (572 $\pm 28 \mathrm{~nm}$ band pass filter) and BL-4 $(675 \pm 30 \mathrm{~nm}$ band pass filter) and a detection channel for a red laser $(640 \mathrm{~nm})$ : BL-3 $(660 \pm 20 \mathrm{~nm}$ band pass filter). Flow cytometry experiments and data analyses were performed using ACEA Novo Express ${ }^{\circledR}$ software (ACEA Biosciences, Inc., San Diego, CA, USA). Fluorescence data were represented in a logarithmic scale.

\subsection{Generation and Detection of Peroxynitrite in Boar Spermatozoa by Flow Cytometry}

SIN-1 was used for the generation of intracellular peroxynitrite, as it has been previously described in human spermatozoa [7]. A stock solution of SIN-1 was prepared at $100 \mathrm{mM}$ in DMSO. Briefly, aliquots of $0.5 \mathrm{~mL}$ boar sperm samples $\left(40 \times 10^{6}\right.$ spermatozoa $\left./ \mathrm{mL}\right)$ were incubated with different concentrations of SIN-1 or DMSO at $38.5^{\circ} \mathrm{C}$ for $1 \mathrm{~h}$. After incubation, sperm samples were incubated with $1 \mu \mathrm{M}$ of the fluorescent probe dihydrorhodamine 123 (DHR 123) at $37^{\circ} \mathrm{C}$ for $20 \mathrm{~min}$ to detect peroxynitrite production in boar spermatozoa. DHR 123 is oxidized by peroxynitrite into rhodamine 123 and not by other oxidants such as $\mathrm{H}_{2} \mathrm{O}_{2}$, superoxide anion $\mathrm{O}_{2}{ }^{\bullet-}$ or $\mathrm{NO}$ [42]. After excitation at $488 \mathrm{~nm}$, rhodamine 123 fluorescence was detected using a $530 \pm 30 \mathrm{~nm}$ band pass filter. Results are expressed as the relative fluorescent intensity (RFI) normalized to the control $\pm \mathrm{SEM}$; the fluorescence values were calculated on the geometric mean fluorescence intensity (MFI) of rhodamine 123. We used RFI because it allows a better estimation of progressive changes in the whole cell population.

\subsection{Analysis of Spermatozoa Viability by Flow Cytometry}

As described previously [22,43], fluorescent staining using SYBR-14 and propidium iodide (PI) was performed to measure sperm viability. Briefly, $5 \mu \mathrm{L}$ of SYBR-14 $(2 \mu \mathrm{M})$ and $10 \mu \mathrm{L}$ of PI $(240 \mu \mathrm{M})$ were added to $100 \mu \mathrm{L}$ of spermatozoa $\left(40 \times 10^{6}\right.$ cells $\left./ \mathrm{mL}\right)$ diluted with $400 \mu \mathrm{L}$ of isotonic buffered diluent, then incubated for $15 \mathrm{~min}$ at room temperature (RT) in darkness and analyzed in the flow cytometer. After excitation at $488 \mathrm{~nm}$, SYBR-14 fluorescence was detected using a $530 \pm 30 \mathrm{~nm}$ band pass filter and PI fluorescence using $675 \pm 30 \mathrm{~nm}$ band pass filter. Results of viable spermatozoa were expressed as the average of the percentage of SYBR $14^{+}$and $\mathrm{PI}^{-}$spermatozoa $\pm \mathrm{SEM}$.

\subsection{Evaluation of the Sperm Acrosome Membrane Integrity by Flow Cytometry}

Acrosome integrity was assessed using PNA-FITC as described previously [43]. Aliquots of $100 \mu \mathrm{L}$ of semen $\left(40 \times 10^{6}\right.$ cells $/ \mathrm{mL}$ ) were incubated (darkness, 5 min at RT) with $2 \mu \mathrm{g} / \mathrm{mL}$ of PNA-FITC and $6 \mu \mathrm{M}$ of PI. Then, $400 \mu \mathrm{L}$ of isotonic buffered diluent were added and mixed before flow cytometry analysis. The fluorescence value of probe PNA-FITC was collected in the BL-1 channel and in the BL-4 channel for PI. Results are expressed as the average of the percentage of $\mathrm{PNA}^{+}$and $\mathrm{PI}^{-}$spermatozoa \pm SEM. 


\subsection{Analysis of Mitochondrial Membrane Potential $(\Delta \Psi m)$ of Boar Spermatozoa by Flow Cytometry}

Variations of mitochondrial membrane potential in boar spermatozoa, $\Delta \Psi \mathrm{m}$, were evaluated using the specific probe JC-1 (5, $5^{\prime}, 6,6^{\prime}$-tetrachloro-1,1',3,3' tetraethylbenzymidazolyl carbocyanine iodine) as described previously $[43,44]$. Briefly, $100 \mu \mathrm{L}$ of spermatozoa $\left(40 \times 10^{6}\right.$ cells/mL $)$ were diluted in $400 \mu \mathrm{L}$ of isotonic buffered diluent containing $0.9 \mu \mathrm{M}$ of JC- 1 and incubated at $38.5^{\circ} \mathrm{C}$ for $30 \mathrm{~min}$. The fluorescence value of JC- 1 was collected on both channels BL- 1 and BL-2. The percentage of orange stained sperm cells was recorded and considered the population of spermatozoa with a relative higher mitochondrial membrane potential. Results are expressed as the average of the percentage of orange stained (high $\Delta \Psi \mathrm{m}$ ) spermatozoa $\pm \mathrm{SEM}$.

\subsection{Analysis of Lipid Peroxidation in Boar Spermatozoa by Flow Cytometry}

Lipid peroxidation (LPO) was assessed using the fluorescent probe C11-BODIPY581/591, which becomes oxidized in contact with reactive species (ROS), as described by Brouwers and Gadella [45] with some modifications. Fluorescence emission of the probe changes according to its state (non peroxidized: red and peroxidized: green), and was detected by flow cytometry. Briefly, sperm samples $\left(40 \times 10^{6}\right.$ cells $\left./ \mathrm{mL}\right)$ were incubated with $2 \mu \mathrm{M}$ of C11-BODIPY ${ }^{581 / 591}$ for $30 \mathrm{~min}$ at $38.5^{\circ} \mathrm{C}$ in TBM. Then, excess of probe C11-BODIPY ${ }^{581 / 591}$ from the medium was removed by centrifugation and experimental treatment of spermatozoa with SIN-1 was carried out. Later, samples were incubated for $30 \mathrm{~min}$ at $38^{\circ} \mathrm{C}$ in darkness with LIVE/DEAD ${ }^{\mathrm{TM}} \mathrm{L} 10120 \mathrm{kit}$ (amine reactive dye) following the manufacturer's instructions. Incubation of spermatozoa with $800 \mu \mathrm{M}$ of $\mathrm{FeSO}_{4}$ as an oxidant inducer served as control sample for lipid peroxidation. The percentage of viable $\left(\mathrm{L} 10120^{-}\right)$spermatozoa with low fluorescence intensity for C11-BODIPY ${ }^{581 / 591}$ was recorded. The fluorescence values of peroxidized C11-BODIPY ${ }^{581 / 591}$ were collected in the BL-1 channel, whereas live/dead cells fluorescence was collected in the BL-3 channel. Results are expressed as the mean of RFI of oxidized C11-BODIPY581/591 \pm SEM in live spermatozoa.

\subsection{Analysis of Plasma Membrane Fluidity in Boar Spermatozoa by Flow Cytometry}

Fluorescent staining using the probes merocyanine M540, as a membrane lipid fluidity marker, and YoPro-1, as a marker of changes in plasma membrane permeability (commonly associated with cell death), was performed as we previously described [46,47]. Briefly, $100 \mu \mathrm{L}$ of spermatozoa $\left(40 \times 10^{6}\right.$ cells $\left./ \mathrm{mL}\right)$ were diluted in $400 \mu \mathrm{L}$ of isotonic buffer containing $75 \mathrm{nM}$ of YoPro-1, mixed and incubated at $38^{\circ} \mathrm{C}$ for $15 \mathrm{~min}$. Then, M540 was added to each sample to a final concentration of $2 \mu \mathrm{M}$, incubated for $2 \mathrm{~min}$ and remixed before flow cytometry analysis. The fluorescence values of probes YoPro-1 and M540 were collected on both BL-1 and BL-2 channels. Labeled spermatozoa were categorized as (i) viable cells with low plasma membrane lipid disorder (YoPro- $1^{-} / \mathrm{M}^{5} 40^{\mathrm{low}}$ ), (ii) viable cells with high plasma membrane lipid disorder (YoPro- $1^{-} / \mathrm{M} 540^{\text {high }}$ ); or (iii) non-viable cells $\left(\right.$ Yo-Pro- $\left.1^{+}\right)$. Results are expressed as the mean of RFI of M540high \pm SEM in live spermatozoa $\left(\right.$ Yo-Pro- $\left.1^{-}\right)$.

\subsection{Evaluation of Boar Spermatozoa Motility}

Boar spermatozoa were incubated with SIN-1 or DMSO at $38.5^{\circ} \mathrm{C}$ in TBM or TCM during $1 \mathrm{~h}$. After gentle mixing $2 \mu \mathrm{L}$ of sperm sample were placed in a $38.5^{\circ} \mathrm{C}$ pre-warmed counting chamber with $20 \mu \mathrm{m}$ depth (Leja ${ }^{\circledR}$, Luzernestraat, The Netherlands) and motility parameters were measured using a microscope equipped with a $10 \times$ negative-phase contrast objective and a heated stage. Analysis was based on the examination of 25 consecutive digitalized images obtained during $1 \mathrm{~s}$ from at least 4 different fields. At least 300 spermatozoa per sample were analyzed. Finally, a CASA system (ISAS ${ }^{\circledR}$ program, Proiser R+D, Paterna, Valencia, Spain) was used to analyze following sperm motility parameters and coefficients: motile spermatozoa (percentage of spermatozoa with an average path velocity $>10 \mu \mathrm{m} / \mathrm{s}$ ), progressive motile spermatozoa (percentage of spermatozoa with a straightness 
coefficient $>80 \%$ ), rapidly progressive spermatozoa (percentage of spermatozoa with VAP velocity $>45 \mu \mathrm{m} / \mathrm{s}$ and STR $>80 \%$ ), curvilinear velocity in $\mu \mathrm{m} / \mathrm{s}$ (VCL), straight-line velocity in $\mu \mathrm{m} / \mathrm{s}$ (VSL), average path velocity in $\mu \mathrm{m} / \mathrm{s}$ (VAP), linearity coefficient in \% (LIN), straightness coefficient in \% (STR), amplitude of lateral head movement in $\mu \mathrm{m}$ (ALH), beat cross of flagellum frequency (BCF), and wobble coefficient in \% (WOB).

\subsection{Analysis of Boar Spermatozoa Phosphorylated Proteins by Western Blotting}

Western blot analysis was performed as previously described [48]. Briefly, spermatozoa (1.5 mL) were centrifuged at $5000 \mathrm{~g}$ for $3 \mathrm{~min}$ at RT and washed in PBS. Pellet was resuspended in $90 \mu \mathrm{L}$ of Laemmli Sample Buffer $(2 \times)$ and then centrifuged at $10.000 \mathrm{~g}$ for $10 \mathrm{~min}$ at $4{ }^{\circ} \mathrm{C}$ and the protein concentration of the supernatant was determined using a Bio-Rad DC Protein Assay. After protein concentration analysis, 2-mercaptoethanol $(2.5 \% ; v / v)$ was added to the sperm lysates before heating for $5 \mathrm{~min}$ at $95^{\circ} \mathrm{C}$. Sperm proteins $(15 \mu \mathrm{g})$ were resolved using $10 \%$ SDS-PAGE and electro-transferred to nitrocellulose membranes. Membranes were incubated at $4{ }^{\circ} \mathrm{C}$ overnight using anti-phospho-GSK- $3 \alpha / \beta$ (1:1.000), anti-phospho-PKA-substrates (1:1.000), or anti- $\alpha$-tubulin (1:5.000) antibodies. Incubations with the appropriate secondary antibody were used and protein bands on the membrane were visualized using ECL detection kit and exposed to Hyperfilm ${ }^{\mathrm{TM}}$ ECL. Individual bands intensity was quantified by densitometry on a gel documentation system using the ImageJ program.

\subsection{Statistical Analysis}

The effects of treatment with SIN-1 at different concentrations were analyzed. In order to show if the differences are statistically significant, hypothesis tests were carried out. Data were analyzed for normal distribution with a Kolmogorov-Smirnov test and for homoscedasticity with a Levene test. When possible, parametric test, as unpaired Students $t$-test or one-way analysis of variance (ANOVA) followed by post-hoc Tukey, were applied (Data in Figure 1, Figure 2, Figure 3, Figure 4, Figure 5, Figure 6 and Table 1). When parametric tests could not be applied, since the data did not meet the applicability conditions (normality and heterocedasticity), nonparametric alternatives were used. Specifically, Kruskal-Wallis test was used to show statistically significant differences among all the groups. When significant results were found, nonparametric pairwise comparisons were used based on the Mann-Whitney U test with the Bonferroni correction (Data in Figures 7 and 9). All data are shown as the mean \pm Standard Error of the Mean (SEM). All analyses were performed using SPSS v19 for Windows software (SPSS Inc. Chicago, IL). Statistical significances were set at $p<0.05$.

Author Contributions: Conceptualization, L.J.G.-M., L.G.-F., and M.J.B.; data curation, R.S. and N.G.; formal analysis, R.S., N.G., and L.J.G.-M.; funding acquisition, L.J.G.-M., L.G.-F., and M.J.B.; investigation, R.S., N.G., and J.A.C.; project administration, L.J.G.-M. and M.J.B.; supervision, L.J.G.-M., L.G.-F. and M.J.B.; validation, L.J.G.-M. and L.G.-F.; visualization, R.S., N.G., and M.J.B.; writing-original draft, R.S., N.G., and M.J.B.; writing-review and editing, L.J.G.-., L.G.-F., and M.J.B. All authors have read and agreed to the published version of the manuscript.

Funding: N. Garrido is recipient of a pre-doctoral Grant from the Fundación Valhondo Calaff in Extremadura (Spain). This work was supported by the following Grants: AGL2015-73249-JIN (AEI/FEDER/UE), JUEX-IB16184, GR15118 and GR18094. L. González-Fernández was supported by regional grant "Atracción y retorno de talento investigador a Centros de $\mathrm{I}+\mathrm{D}+\mathrm{i}$ " that belongs to regional system of science "Sistema Extremeño de Ciencia, Tecnología e Innovación" (TA18008) from "Junta de Extremadura, Spain".

Conflicts of Interest: The authors declare no conflict of interest.

\section{References}

1. Herrero, M.B.; Perez Martinez, S.; Viggiano, J.M.; Polak, J.M.; de Gimeno, M.F. Localization by indirect immunofluorescence of nitric oxide synthase in mouse and human spermatozoa. Reprod. Fertil. Dev. 1996, 8, 931-934. [CrossRef] [PubMed]

2. Lee, N.P.; Cheng, C.Y. Nitric oxide/nitric oxide synthase, spermatogenesis, and tight junction dynamics. Biol. Reprod. 2004, 70, 267-276. [CrossRef] [PubMed] 
3. Lee, N.P.; Cheng, C.Y. Nitric oxide and cyclic nucleotides: Their roles in junction dynamics and spermatogenesis. Adv. Exp. Med. Biol. 2008, 636, 172-185. [CrossRef] [PubMed]

4. Doshi, S.B.; Khullar, K.; Sharma, R.K.; Agarwal, A. Role of reactive nitrogen species in male infertility. Reprod. Biol. Endocrinol. 2012, 10, 109. [CrossRef] [PubMed]

5. Morielli, T.; O'Flaherty, C. Oxidative stress impairs function and increases redox protein modifications in human spermatozoa. Reproduction 2015, 149, 113-123. [CrossRef]

6. Salvolini, E.; Buldreghini, E.; Lucarini, G.; Vignini, A.; Di Primio, R.; Balercia, G. Nitric oxide synthase and tyrosine nitration in idiopathic asthenozoospermia: An immunohistochemical study. Fertil. Steril. 2012, 97, 554-560. [CrossRef]

7. Uribe, P.; Boguen, R.; Treulen, F.; Sanchez, R.; Villegas, J.V. Peroxynitrite-Mediated nitrosative stress decreases motility and mitochondrial membrane potential in human spermatozoa. Mol. Hum. Reprod. 2015, 21, 237-243. [CrossRef]

8. Uribe, P.; Treulen, F.; Boguen, R.; Sanchez, R.; Villegas, J.V. Nitrosative stress by peroxynitrite impairs ATP production in human spermatozoa. Andrologia 2017, 49. [CrossRef]

9. Vignini, A.; Nanetti, L.; Buldreghini, E.; Moroni, C.; Ricciardo-Lamonica, G.; Mantero, F.; Boscaro, M.; Mazzanti, L.; Balercia, G. The production of peroxynitrite by human spermatozoa may affect sperm motility through the formation of protein nitrotyrosine. Fertil. Steril. 2006, 85, 947-953. [CrossRef]

10. Cabrillana, M.E.; Uribe, P.; Villegas, J.V.; Alvarez, J.; Sanchez, R.; Fornes, M.W. Thiol oxidation by nitrosative stress: Cellular localization in human spermatozoa. Syst. Biol. Reprod. Med. 2016, 62, 325-334. [CrossRef]

11. Zhang, H.; Zheng, R.L. Possible role of nitric oxide on fertile and asthenozoospermic infertile human sperm functions. Free Radic. Res. 1996, 25, 347-354. [CrossRef] [PubMed]

12. Lewis, S.E.; Donnelly, E.T.; Sterling, E.S.; Kennedy, M.S.; Thompson, W.; Chakravarthy, U. Nitric oxide synthase and nitrite production in human spermatozoa: Evidence that endogenous nitric oxide is beneficial to sperm motility. Mol. Hum. Reprod. 1996, 2, 873-878. [CrossRef] [PubMed]

13. Herrero, M.B.; de Lamirande, E.; Gagnon, C. Tyrosine nitration in human spermatozoa: A physiological function of peroxynitrite, the reaction product of nitric oxide and superoxide. Mol. Hum. Reprod. 2001, 7, 913-921. [CrossRef] [PubMed]

14. Rodriguez, P.C.; O’Flaherty, C.M.; Beconi, M.T.; Beorlegui, N.B. Nitric oxide induces acrosome reaction in cryopreserved bovine spermatozoa. Andrologia 2005, 37, 166-172. [CrossRef]

15. Koppenol, W.H. The basic chemistry of nitrogen monoxide and peroxynitrite. Free Radic. Biol. Med. 1998, 25, 385-391. [CrossRef]

16. Rodriguez, P.C.; Beconi, M.T. Peroxynitrite participates in mechanisms involved in capacitation of cryopreserved cattle. Anim. Reprod. Sci. 2009, 110, 96-107. [CrossRef]

17. Pacher, P.; Beckman, J.S.; Liaudet, L. Nitric oxide and peroxynitrite in health and disease. Physiol. Rev. 2007, 87, 315-424. [CrossRef]

18. Negre-Salvayre, A.; Coatrieux, C.; Ingueneau, C.; Salvayre, R. Advanced lipid peroxidation end products in oxidative damage to proteins. Potential role in diseases and therapeutic prospects for the inhibitors. Br. J. Pharmacol. 2008, 153, 6-20. [CrossRef]

19. Uribe, P.; Cabrillana, M.E.; Fornes, M.W.; Treulen, F.; Boguen, R.; Isachenko, V.; Isachenko, E.; Sanchez, R.; Villegas, J.V. Nitrosative stress in human spermatozoa causes cell death characterized by induction of mitochondrial permeability transition-driven necrosis. Asian J. Androl. 2018, 20, 600-607. [CrossRef]

20. Khosravi, F.; Valojerdi, M.R.; Amanlou, M.; Karimian, L.; Abolhassani, F. Relationship of seminal reactive nitrogen and oxygen species and total antioxidant capacity with sperm DNA fragmentation in infertile couples with normal and abnormal sperm parameters. Andrologia 2014, 46, 17-23. [CrossRef]

21. Oztezcan, S.; Turkoglu, U.M.; Kervancioglu, E.; Kocak, T.; Kocak-Toker, N.; Aykac-Toker, G. In Vitro effects of peroxynitrite on human spermatozoa. Andrologia 1999, 31, 195-198. [CrossRef] [PubMed]

22. Hurtado de Llera, A.; Martin-Hidalgo, D.; Gil, M.C.; Garcia-Marin, L.J.; Bragado, M.J. AMPK up-activation reduces motility and regulates other functions of boar spermatozoa. Mol. Hum. Reprod. 2015, 21, 31-45. [CrossRef] [PubMed]

23. Crow, J.P. Peroxynitrite scavenging by metalloporphyrins and thiolates. Free Radic. Biol. Med. 2000, 28, 1487-1494. [CrossRef]

24. Zhang, X.G.; Yan, G.J.; Hong, J.Y.; Su, Z.Z.; Yang, G.S.; Li, Q.W.; Hu, J.H. Effects of bovine serum albumin on boar sperm quality during liquid storage at $17^{\circ} \mathrm{C}$. Reprod. Domest. Anim. 2015, 50, 263-269. [CrossRef] 
25. Zini, A.; De Lamirande, E.; Gagnon, C. Low levels of nitric oxide promote human sperm capacitation In Vitro. J. Androl. 1995, 16, 424-431.

26. Aitken, R.J.; Baker, M.A.; Nixon, B. Are sperm capacitation and apoptosis the opposite ends of a continuum driven by oxidative stress? Asian J. Androl. 2015, 17, 633-639. [CrossRef]

27. Staicu, F.D.; Lopez-Ubeda, R.; Romero-Aguirregomezcorta, J.; Martinez-Soto, J.C.; Matas Parra, C. Regulation of boar sperm functionality by the nitric oxide synthase/nitric oxide system. J. Assist. Reprod. Genet. 2019, 36, 1721-1736. [CrossRef]

28. Hou, M.L.; Huang, S.Y.; Lai, Y.K.; Lee, W.C. Geldanamycin augments nitric oxide production and promotes capacitation in boar spermatozoa. Anim. Reprod. Sci. 2008, 104, 56-68. [CrossRef]

29. O'Flaherty, C. Redox regulation of mammalian sperm capacitation. Asian J. Androl. 2015, 17, 583-590. [CrossRef]

30. Agarwal, A.; Virk, G.; Ong, C.; du Plessis, S.S. Effect of oxidative stress on male reproduction. World J. Mens Health 2014, 32, 1-17. [CrossRef]

31. O'Flaherty, C.; Matsushita-Fournier, D. Reactive oxygen species and protein modifications in spermatozoa. Biol. Reprod. 2017, 97, 577-585. [CrossRef] [PubMed]

32. Storey, B.T. Biochemistry of the induction and prevention of lipoperoxidative damage in human spermatozoa. Mol. Hum. Reprod. 1997, 3, 203-213. [CrossRef] [PubMed]

33. Cruz, D.F.; Fardilha, M. Relevance of peroxynitrite formation and 3-nitrotyrosine on spermatozoa physiology. Porto Biomed. J. 2016, 1, 129-135. [CrossRef]

34. Herrero, M.B.; de Lamirande, E.; Gagnon, C. Nitric oxide regulates human sperm capacitation and protein-tyrosine phosphorylation In Vitro. Biol. Reprod. 1999, 61, 575-581. [CrossRef] [PubMed]

35. Aparicio, I.M.; Bragado, M.J.; Gil, M.C.; Garcia-Herreros, M.; Gonzalez-Fernandez, L.; Tapia, J.A.; Garcia-Marin, L.J. Porcine sperm motility is regulated by serine phosphorylation of the glycogen synthase kinase-3alpha. Reproduction 2007, 134, 435-444. [CrossRef]

36. Bragado, M.J.; Aparicio, I.M.; Gil, M.C.; Garcia-Marin, L.J. Protein kinases A and C and phosphatidylinositol 3 kinase regulate glycogen synthase kinase-3A serine 21 phosphorylation in boar spermatozoa. J. Cell. Biochem. 2010, 109, 65-73. [CrossRef]

37. Mizrahi, R.; Breitbart, H. Mitochondrial PKA mediates sperm motility. Biochim. Biophys. Acta 2014, 1840, 3404-3412. [CrossRef]

38. Fisch, A.; Michael-Hepp, J.; Meyer, J.; Darius, H. Synergistic interaction of adenylate cyclase activators and nitric oxide donor SIN-1 on platelet cyclic AMP. Eur. J. Pharmacol. 1995, 289, 455-461. [CrossRef]

39. Grenegard, M.; Gustafsson, M.C.; Andersson, R.G.; Bengtsson, T. Synergistic inhibition of thrombin-induced platelet aggregation by the novel nitric oxide-donor GEA 3175 and adenosine. Br. J. Pharmacol. 1996, 118, 2140-2144. [CrossRef]

40. Bassil, M.; Li, Y.; Anand-Srivastava, M.B. Peroxynitrite inhibits the expression of $\mathrm{G}_{\mathrm{i}}$ alpha protein and adenylyl cyclase signaling in vascular smooth muscle cells. Am. J. Physiol. Heart Circ. Physiol. 2008, 294, H775-H784. [CrossRef]

41. Tommasini, I.; Cerioni, L.; Palomba, L.; Cantoni, O. Prostaglandin $\mathrm{E}_{2}$ signals monocyte/macrophage survival to peroxynitrite via protein kinase A converging in bad phosphorylation with the protein kinase C alpha-dependent pathway driven by 5-hydroxyeicosatetraenoic acid. J. Immunol. 2008, 181, 5637-5645. [CrossRef]

42. Crow, J.P. Dichlorodihydrofluorescein and dihydrorhodamine 123 are sensitive indicators of peroxynitrite in vitro: Implications for intracellular measurement of reactive nitrogen and oxygen species. Nitric Oxide 1997, 1, 145-157. [CrossRef]

43. Martin-Hidalgo, D.; Hurtado de Llera, A.; Yeste, M.; Gil, M.C.; Bragado, M.J.; Garcia-Marin, L.J. Adenosine monophosphate-activated kinase, AMPK, is involved in the maintenance of the quality of extended boar semen during long-term storage. Theriogenology 2013, 80, 285-294. [CrossRef]

44. Hurtado de Llera, A.; Martin-Hidalgo, D.; Rodriguez-Gil, J.E.; Gil, M.C.; Garcia-Marin, L.J.; Bragado, M.J. AMP-activated kinase, AMPK, is involved in the maintenance of plasma membrane organization in boar spermatozoa. Biochim. Biophys. Acta 2013, 1828, 2143-2151. [CrossRef]

45. Brouwers, J.F.; Gadella, B.M. In situ detection and localization of lipid peroxidation in individual bovine sperm cells. Free Radic. Biol. Med. 2003, 35, 1382-1391. [CrossRef] 
46. Hurtado de Llera, A.; Martin-Hidalgo, D.; Gil, M.C.; Garcia-Marin, L.J.; Bragado, M.J. The Calcium/CaMKKalpha/beta and the cAMP/PKA pathways are essential upstream regulators of AMPK activity in boar spermatozoa. Biol. Reprod. 2014, 90, 29. [CrossRef]

47. Martin-Hidalgo, D.; Baron, F.J.; Bragado, M.J.; Carmona, P.; Robina, A.; Garcia-Marin, L.J.; Gil, M.C. The effect of melatonin on the quality of extended boar semen after long-term storage at $17^{\circ} \mathrm{C}$. Theriogenology 2011, 75, 1550-1560. [CrossRef]

48. Macias-Garcia, B.; Garcia-Marin, L.J.; Bragado, M.J.; Gonzalez-Fernandez, L. The calcium-sensing receptor regulates protein tyrosine phosphorylation through PDK1 in boar spermatozoa. Mol. Reprod. Dev. 2019, 86, 751-761. [CrossRef]

(C) 2020 by the authors. Licensee MDPI, Basel, Switzerland. This article is an open access article distributed under the terms and conditions of the Creative Commons Attribution (CC BY) license (http://creativecommons.org/licenses/by/4.0/). 